\title{
A comparison of pertussis rates in the Northwest Territories: Pre- and postacellular pertussis vaccine introduction in children and adolescents
}

\author{
Kami Kandola MD MPH${ }^{1}$, Amy Lea RN BA ${ }^{2}$, Wanda White RN BSN MHS ${ }^{3}$, Maria Santos $\mathrm{MSc}^{3}$
}

\begin{abstract}
K Kandola, A Lea, W White, M Santos. A comparison of pertussis rates in the Northwest Territories: Pre-and postacellular pertussis vaccine introduction in children and adolescents. Can J Infect Dis Med Microbiol 2005;16(5):271-274.
\end{abstract}

INTRODUCTION: During the past decade, a trend toward increasing cases of Bordetella pertussis in older children and adults has been witnessed in Canada. The National Advisory Committee on Immunization now recommends that the adult formulation of the acellular pertussis (adult dTap) vaccine combined with diphtheria and tetanus toxoids be substituted for diphtheria and tetanus toxoids alone for the 14- to 16-year-old booster dose. In October 2000, the government of the Northwest Territories was one of the first to adopt adult dTap into their territorial immunization program free of charge.

OBJECTIVE: To evaluate the effect of the acellular pertussis vaccine in children and adolescents on the epidemiology of pertussis in the Northwest Territories.

METHODS: Pertussis is a reportable disease in the Northwest Territories, and data on the incidence rates of pertussis are available from 1989 to 2004. The present study reviews pertussis cases during three four-year periods: the whole-cell vaccine era (1993 to 1996); the preadult dTap era (1997 to 2000); and the postadult dTap era (2001 to 2004).

RESULTS: The incidence of pertussis decreased from 18.0 cases per 10,000 population in 1993 to 0.2 cases per 10,000 population in 2004 . The number of cases decreased from 186 to 129 to 19 cases in the three chronological time periods (ie, whole-cell vaccine era, preadult dTap era and postadult dTap era, respectively), with the most substantial reduction coming with the introduction of postadult dTap.

CONCLUSIONS: There appears to be a decrease in the incidence of pertussis with the targeted introduction of adult dTap in the Northwest Territories.

Key Words: Acellular pertussis; Adolescent; Targeted; Vaccine
Une comparaison des taux de coqueluche dans les Territoires du Nord-Ouest : Avant et après l'implantation du vaccin acellulaire contre la coqueluche chez les enfants et les adolescents

HISTORIQUE : Depuis dix ans, on remarque une tendance vers l'augmentation des cas de Bordetella pertussis chez les enfants plus âgés et les adultes du Canada. Le Comité consultatif national de l'immunisation recommande désormais que la formulation adulte du vaccin acellulaire contre la coqueluche (dTca pour adulte), associée aux anatoxines diphtérique et tétanique, remplace celle des seules anatoxines diphtérique et tétanique au moment de la dose de rappel, entre 14 et 16 ans. En octobre 2000, le gouvernement des Territoires du Nord-Ouest a été l'un des premiers à offrir le vaccin dTca pour adulte sans frais dans le cadre de son programme territorial de vaccination.

OBJECTIF : La présente étude permet d'évaluer l'effet de l'administration du vaccin acellulaire contre la coqueluche chez les enfants et les adolescents sur l'épidémiologie de la coqueluche dans les Territoires du Nord-Ouest.

MÉTHODOLOGIE : La coqueluche est une maladie à déclaration obligatoire dans les Territoires du Nord-Ouest, et des données sur les taux d'incidence de coqueluche sont disponibles de 1989 à 2004. La présente étude passe en revue les cas de coqueluche pendant trois périodes de quatre ans : L'époque du vaccin à cellule complète (de 1993 à 1996), l'époque précédant celle du vaccin dTca pour adulte (de 1997 à 2000) et l'époque du vaccin dTca pour adulte (de 2001 à 2004).

RÉSULTATS : L'incidence de coqueluche a fléchi de 18,0 cas pour 10000 habitants en 1993 à 0,2 cas pour 10000 habitants en 2004. Le nombre de cas a chuté de 186 à 129 , puis à 19 pendant les trois périodes chronologiques (c.-à-d., époque du vaccin à cellule complète, époque précédant celle du vaccin dTca pour adulte et époque du vaccin dTca pour adulte, respectivement), la réduction la plus substantielle étant apparue depuis l'implantation du vaccin dTca pour adulte.

CONCLUSIONS : On semble observer une diminution de l'incidence de coqueluche depuis l'implantation ciblée du vaccin dTca pour adulte dans les Territoires du Nord-Ouest.

increasing trends of infection in adolescents and adults. These increases have been attributed to waning immunity in later childhood (6).

In May 2000, the National Advisory Committee on Immunization (7) recommended that the adult formulation of the acellular pertussis (adult dTap) vaccine combined with diphtheria and tetanus toxoids be substituted for diphtheria and tetanus toxoids (Td) alone for the 14- to 16-year-old booster dose. Although there are two formulations of adult Canada (1). A number of other studies (2-5) in Australia, Japan, Germany and the United States have also shown

${ }^{1}$ Stanton Territorial Health Authority; ${ }^{2}$ Yellowknife Health and Social Services; ${ }^{3}$ Department of Health and Social Services, Yellowknife,

Northwest Territories

Correspondence and reprints: Dr Kami Kandola, Stanton Territorial Health Authority, PO Box 10, Yellowknife, Northwest Territories

X1A 2N1. Telephone 867-669-9032, fax 867-669-7517, e-mail kami_kandola@gov.nt.ca

Received for publication February 21, 2005. Accepted June 13, 2005 
Clinical case: (a) Paroxysmal cough, or cough with gagging or vomiting $\geq 7$ days; (b) cough with apnea with no other known cause; (c) cough with inspiratory whoop with no other known cause.

Confirmed case (clinical): Contact with a laboratoryconfirmed case and presenting with symptoms of any duration with no known cause (referred to in the text as an 'epi-linked case').

Confirmed case (laboratory): Positive culture for Bordetella pertussis (referred to in the text as a 'laboratoryconfirmed case').

Figure 1) Case definitions for pertussis in the Northwest Territories

dTap, only the Adacel vaccine (Sanofi Pasteur, Canada) is available in Canada (8). In October 2000, the government of the Northwest Territories was one of the first to adopt adult dTap into their territorial immunization program free of charge for adolescents aged 14 to 16 years. Implementation of this policy occurred in early 2001.

\section{OBJECTIVE}

The objective of the present study was to evaluate the effect of implementing the acellular pertussis vaccine first in childhood and then in adolescence on the epidemiology of pertussis in the Northwest Territories.

The present study compared pertussis cases in three consecutive four-year periods: the whole-cell vaccine era; the preadult dTap era, which occurred after the introduction of the child formulation of the acellular pertussis vaccine; and the postadult dTap era, which followed the introduction of the adult formulation of the acellular pertussis vaccine.

\section{METHODS}

Pertussis is a reportable disease in the Northwest Territories and surveillance standards have remained unchanged in the past decade. Persons who met the clinical case definition of pertussis (Figure 1) received a nasopharyngeal swab, which was sent for culture to the Provincial Laboratory of Public Health in Edmonton, Alberta. A clinically confirmed case (hereinafter referred to as an 'epi-linked case') would have been in contact with a laboratory-confirmed case. In this situation, epi-linked cases can present with symptoms while the laboratory test is pending. In an outbreak situation, a clinical case is considered to be a patient who has met the clinical criteria with no other known cause and has a laboratory test pending. Diagnoses of clinical cases are reported by public health nurses, community nurses or physicians, but only during major outbreak periods, such as in 1993 and 1999 (Table 1).

The routine case management protocol for clinicians is provided by the Department of Health and Social Services within their territorial communicable disease manual. All epi-linked and clinical cases are swabbed and provided with treatment. In terms of the contact management protocol, a change in protocol occurred in 2004. Initially, all household and home daycare contacts were provided with chemoprophylaxis regardless of age and immunization status. As of 2004, only household contacts (including attendees at family daycare centres) with a vulnerable person present (ie, an infant younger than one year of age [vaccinated or not] or a pregnant women in her third trimester) are treated. Furthermore, vulnerable persons in the community who have had face-to-face
TABLE 1

Annual incidence of pertussis in the Northwest Territories

\begin{tabular}{lcrrrr}
\hline & \multicolumn{4}{c}{ Number of pertussis cases } & \\
\cline { 2 - 4 } Year & Clinical & $\begin{array}{c}\text { Epi- } \\
\text { linked* }\end{array}$ & $\begin{array}{c}\text { Laboratory- } \\
\text { confirmed }\end{array}$ & Total & $\begin{array}{c}\text { Rate per 10,000 } \\
\text { population (Cl) }\end{array}$ \\
\hline 1993 & 40 & 20 & 72 & 132 & $33.1(27.4-38.7)$ \\
1994 & 0 & 1 & 4 & 5 & $1.2(0.4-2.9)$ \\
1995 & 0 & 0 & 12 & 12 & $2.9(1.5-5.1)$ \\
1996 & 0 & 2 & 35 & 37 & $8.9(6.2-12.2)$ \\
1997 & 0 & 0 & 19 & 19 & $4.6(2.7-7.1)$ \\
1998 & 0 & 0 & 14 & 14 & $3.4(1.9-5.8)$ \\
1999 & 5 & 6 & 77 & 88 & $21.6(17.4-26.7)$ \\
2000 & 0 & 0 & 8 & 8 & $2.0(0.9-3.9)$ \\
2001 & 0 & 0 & 4 & 4 & $1.0(0.3-2.5)$ \\
2002 & 0 & 0 & 13 & 13 & $3.1(1.7-5.4)$ \\
2003 & 0 & 0 & 1 & 1 & $0.2(0.0-1.3)$ \\
2004 & 0 & 0 & 1 & 1 & $0.2(0.0-1.3)$ \\
\hline
\end{tabular}

${ }^{*}$ Clinical case that has been in contact with a laboratory-confirmed case

exposure and/or have shared confined air with a confirmed case for more than $1 \mathrm{~h}$ are also treated.

In terms of the chronology of the pertussis vaccine in the Northwest Territories, neither the child nor the adult formulation of the acellular pertussis vaccine had been introduced in the period from 1993 to 1996. During this time, the diphtheria and tetanus toxoids and the whole-cell pertussis vaccine were provided to infants at two, four, six and 18 months and four to six years of age. The new childhood formulation of the acellular pertussis vaccine was recommended by the National Advisory Committee on Immunization in 1997 and had fewer side effects. From 1997 to 2000 in the Northwest Territories, the child acellular pertussis vaccine had replaced the diphtheria and tetanus toxoids and the whole-cell pertussis vaccine, but dTap had not yet been initiated. Full implementation of this childhood series occurred within the first year of the vaccine introduction in 1997. From 2001 to 2004, both the child and adult formulations of the acellular pertussis vaccine had been introduced. Again, full implementation of the adult formulation occurred within the first year of the vaccine's introduction in October 2000.

A review of vaccine coverage rates for the child formulation of the acellular pertussis vaccine was conducted by the government of the Northwest Territories and is available for 2000 and 2002. Vaccine coverage for dTap in 2003 was calculated for the 17-year-old cohort through review of an existing computerized database and immunization cards. Given that dTap was introduced in 2001 to high school students aged 14 to 16 years, this cohort was eligible for dTap vaccination at several opportunities.

\section{RESULTS}

Incidence rates for laboratory-confirmed pertussis cases from 1990 to 2004 are presented in Figure 2. Table 1 illustrates the total incidence rate for the three types of cases that currently require the notification of the Office of the Chief Medical Health Officer. Data on epi-linked and clinical cases were not electronically captured before 1993; thus, data are only provided from 1993 to 2004 . Figure 2 shows that there were two large outbreaks of pertussis in 1993 and 1999, but none after the introduction of dTap in 2001. The average incidence of laboratory-confirmed pertussis from 1993 to 1996 was 7.5 cases per 10,000 population compared with 7.2 cases 


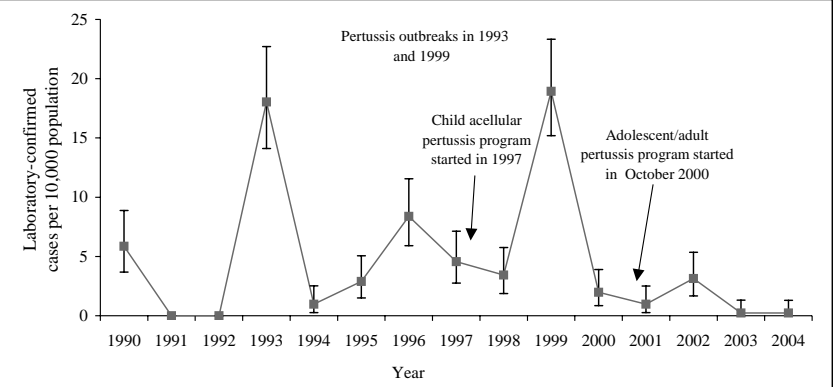

Figure 2) Annual pertussis incidence rates in the Northwest Territories from January 1990 to December 2004 (laboratory-confirmed cases per 10,000 population)

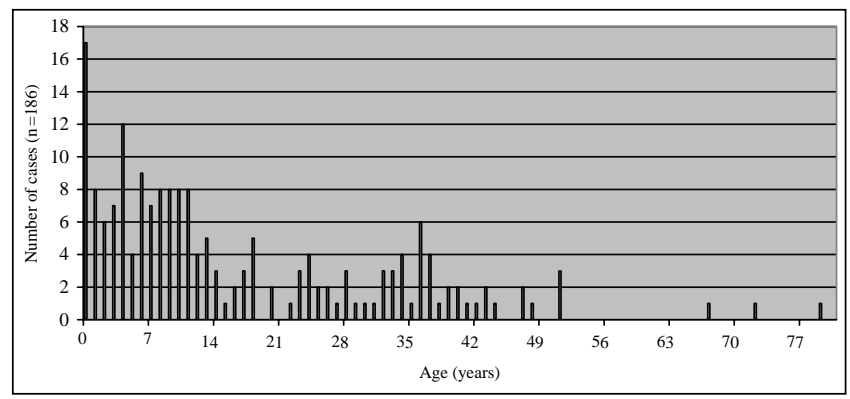

Figure 3) Total number of pertussis cases from 1993 to 1996 in the Northwest Territories (whole-cell vaccine era)

per 10,000 population from 1997 to 2000 and 1.1 cases per 10,000 population from 2001 to 2004. In 2000, before the introduction of adult dTap, child dTap vaccine coverage was $89 \%$; in 2002 , coverage was $87 \%$. In 2003 , vaccine coverage for adult dTap was $84 \%$ in the Northwest Territories for the 17-year-old cohort.

There have been 31 cases of pertussis in infants younger than 12 months of age in which the primary cause was a lack of immunization or partial vaccination: 17 cases from 1993 to 1996 (four cases under two months of age); nine cases from 1997 to 2000 (two cases under two months of age); and five cases from 2001 to 2004 (two cases under two months of age).

Of interest, only one teenager contracted pertussis after adult dTap; however, this was a 14-year-old adolescent with no history of prior vaccination.

\section{DISCUSSION}

Throughout the three observed time periods shown in Figures 3, 4 and 5, there appears to be a greater reduction in pertussis cases among older children than among infants, with the majority of pertussis activity shifting from early childhood (Figure 3) to late childhood, and from late adolescence (Figure 4) to infancy (Figure 5). Nonetheless, the high adult dTap vaccine coverage in 14 - to 16 -year-olds appears to have contributed to the largest reduction in pertussis incidence in the total population. This finding makes sense considering the relatively young demographics of the Northwest Territories compared with Canada overall.

Approximately one-third of all residents in the Northwest Territories are 18 years of age or younger (9). A significant number of births also occur in young mothers; $11 \%$ to $12 \%$ of all births in the Northwest Territories occur in women aged 19 years of age or younger (10). Protecting this age group against

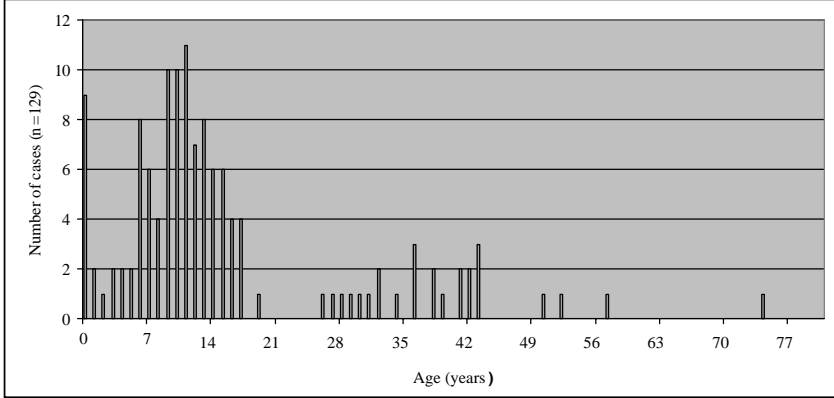

Figure 4) Total number of pertussis cases from 1997 to 2000 in the Northwest Territories (postchild and preadult acellular pertussis vaccine)

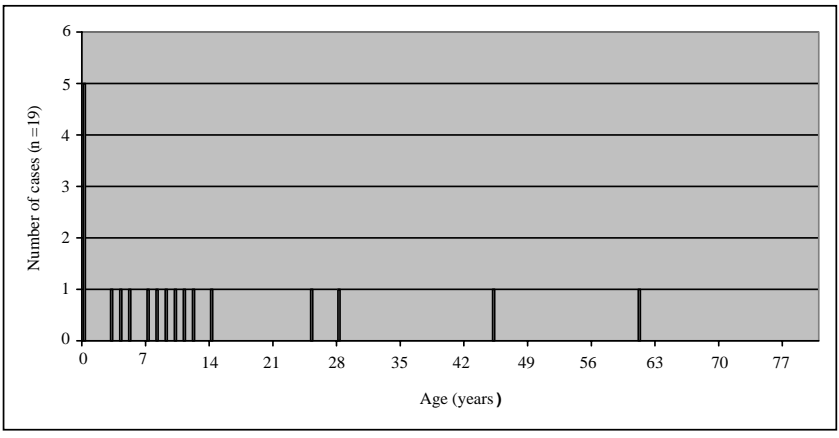

Figure 5) Total number of pertussis cases from 2001 to 2004 in the Northwest Territories (postadult acellular pertussis vaccine)

pertussis would curtail the endemic reservoir for circulation of $B$ pertussis. This significant reduction was not seen when switching to the child formulation of the acellular pertussis vaccine in 1997, although an upward age shift for contracting pertussis did occur, as seen in the 1999 outbreak.

The outbreak in 1999 occurred after a track meet and fanned out among communities and among teenagers in Nunavut. This could possibly explain the higher proportion of teenagers affected by the disease (approximately 23\%). Although the source occurred among teenagers, the increase was not as significant in the younger age groups because of the introduction of the childhood acellular pertussis vaccine at high coverage rates. Nonetheless, teenagers served as the initial reservoir for this outbreak, which spread mainly to older children, adults and infants.

Although the Northwest Territories is a small jurisdiction, the implications of these findings have relevance for other provinces and territories that have recently introduced the acellular pertussis vaccine into their adolescent population. It is important to maintain high coverage in the adolescent population. Ideally, the school system is the best venue for immunization programs, and these programs should be started as soon as possible, before decreased enrollment rates. Street youths and other out-of-school youths should be captured by other means. It would then be important to analyze the impact of this immunization strategy on pertussis trends and adjust the program accordingly. Given the number of pertussis cases in infants younger than two months of age who would not be eligible for the vaccine, the vaccination of young mothers who may be at increased risk should also be considered. This selective approach to vaccination provides greater financial savings than targeting the public in general.

Another important issue is the occurrence of pertussis in the elderly; at least six cases have been reported in individuals 
older than 55 years of age. Nonetheless, the adult formulation of the acellular pertussis vaccine is indicated only for adults younger than 55 years of age. This is primarily due to the lack of research in this age cohort and not due to adverse sequelae; in fact, Sanofi Pasteur (Canada) is looking at relaxing the upper limit of their age restriction. It may be useful to consider targeting this vaccination to seniors who are at a higher risk for morbidity from $B$ pertussis infection due to weakened immune response, frailty and concomitant chronic disease.

\section{Data limitations}

The present study was limited by the small numbers in the Northwest Territories; both the population size and the number of reported pertussis cases are relatively small. As a result, on an annual basis, any increase or decrease in the number of reported cases creates unstable rates, as shown in the confidence intervals in Figure 2.

The cycle in which pertussis outbreaks occur in the Northwest Territories can be attributed to the geography and demographics of the population. Given that communities in the Northwest Territories are relatively small and isolated, a susceptible population may be lacking for a number of years after the occurrence of a large outbreak. Examining the incidence rates shown in Figure 2, the Northwest Territories has particularly large outbreaks every six years (1993 and 1999), with smaller outbreaks between these peaks (1990, 1996 and 2002). From this observation, it appears that an outbreak occurs every three years. The rates seen in 2001 may simply reflect the normal cycle, with just a smaller than usual peak in 2002. If dTap had no effect, then one would predict a large outbreak in 2005 (or 2006). Consequently, these two years will be critical for assessing the program. Nonetheless, there have been only five laboratoryconfirmed cases throughout four different communities by the middle of 2005, which translates into a mid-year rate of 1.2 laboratory-confirmed cases per 10,000 population. Of the laboratory-confirmed cases, two were infants that were not immunized, two were preschoolers that were fully immunized and one was an adult whose immunization status was unknown.

Immunization coverage rates are also subject to systematic errors during the data collection process. The most reliable method for capturing this information is through immunization cards. However, residents of the Northwest Territories are

\section{REFERENCES}

1. Canadian Paediatric Society. Acellular pertussis vaccine for adolescents. Paediatr Child Health 2003;8:378.

2. Robertson PW, Goldberg H, Jarvie BH, Smith DD, Whybin LR. Bordetella pertussis infection: A cause of persistent cough in adults. Med J Aust 1987;146:522-5.

3. Cromer BA, Goydos J, Hackell J, Mezzatesta J, Dekker C, Mortimer EA. Unrecognized pertussis infection in adolescents. Am J Dis Child 1993;147:575-7.

4. Aoyama T, Takeuchi Y, Goto A, Iwai H, Murase Y, Iwata T. Pertussis in adults. Am J Dis Child 1992;146:163-6.

5. Schmitt-Grohe S, Cherry JD, Heininger U, Uberall MA, Pineda E, Stehr K. Pertussis in German adults. Clin Infect Dis 1995;21:860-6

6. Le T, Cherry JD, Chang SJ, et al. Immune responses and antibody decay after immunization of adolescents and adults with an acellular pertussis vaccine: The APERT Study. J Infect Dis 2004;190:535-44

7. National Advisory Committee on Immunization. Canadian Immunization Guide, 6th edn. Ottawa: Canadian Medical Association, 2002:56. transient and can move between communities, as well as in and out of the territory. As a result, information can be missed if it was not captured on a child's immunization card that he or she had been immunized outside of the territory.

Another issue in determining the immunization coverage rate is in relation to the denominator. To account for the transient nature of the territorial population, the cohort was determined based on information from the health care registration database. The cohort was developed based on those born from January 1, 1986, to December 31, 1986, and who resided in the Northwest Territories throughout the age of 14 to 17 years. Furthermore, any individual who had received a $\mathrm{Td}$ or $\mathrm{Td}$ polio adsorbed immunization at least two years before implementation of the adolescent/adult acellular implementation program was discarded from the cohort because these individuals would not have received dTap so soon after receiving $\mathrm{Td}$ or Td polio adsorbed immunization. It has been recognized that a centralized immunization registry will help to create more accurate information concerning vaccinations.

\section{CONCLUSIONS}

In the 14- to 16-year-old cohort, there appears to be an overall decrease in the incidence of pertussis after the introduction of adult dTap in the Northwest Territories. Although there is significant adult dTap coverage for travellers and health care workers, the data support the fact that adolescents seem to be the primary reservoir for transmission to infants and young children. Therefore, cohort by cohort, the universal immunization of adolescents along with health care workers seems sufficient to protect this vulnerable population (11). In fact, this strategy has been supported by a number of studies and is cost-effective compared with the mass immunization of adults $(12,13)$. Nonetheless, the increasing proportion of infant cases within the first two months of life is of concern (despite the overall absolute reduction in cases). Further research on maternal vaccination programs aimed at reducing the incidence of pertussis in the newborn period will be required.

ACKNOWLEDGEMENT: The authors thank the Department of Health and Social Services (Government of Northwest Territories) for their help with this study.

8. National Advisory Committee on Immunization. Statement on adult/adolescent formulation of combined acellular pertussis, tetanus, and diphtheria vaccine. Canadian Communicable Disease Report, 2000

9. Northwest Territories Bureau of Statistics. 2001 Census. <www.stats.gov.nt.ca/Statinfo/Census/census2001/Age-Sex.xls> (Version current at September 20, 2005).

10. Northwest Territories Bureau of Statistics. Births to females less than or equal to 19 years of age: Northwest Territories, 1991-2003. <http://www.stats.gov.nt.ca/statinfo/generalstats/scan/scan.html> (Version current at October 3, 2005).

11. von Konig CH, Halperin S, Riffelmann M, Guiso N. Pertussis of adults and infants. Lancet Infect Dis 2002;2:744-50.

12. Purdy KW, Hay JW, Botteman MF, Ward JI. Evaluation of strategies for use of acellular pertussis vaccine in adolescents and adults: A cost-benefit analysis. Clin Infect Dis 2004;39:20-8

13. Edmunds WJ, Brisson M, Melegaro A, Gay NJ. The potential cost-effectiveness of acellular pertussis booster vaccination in England and Wales. Vaccine 2002;20:1316-30. 


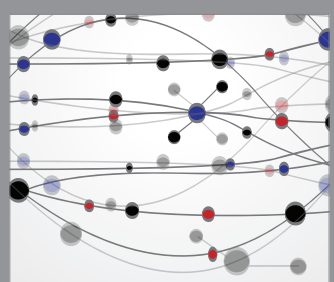

The Scientific World Journal
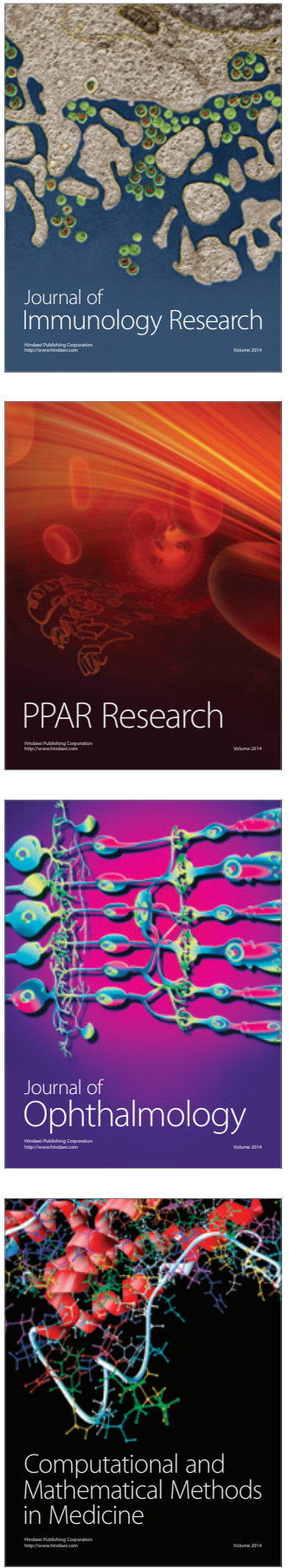

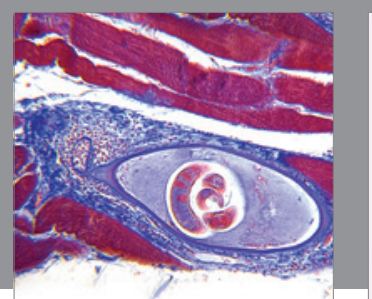

Gastroenterology Research and Practice

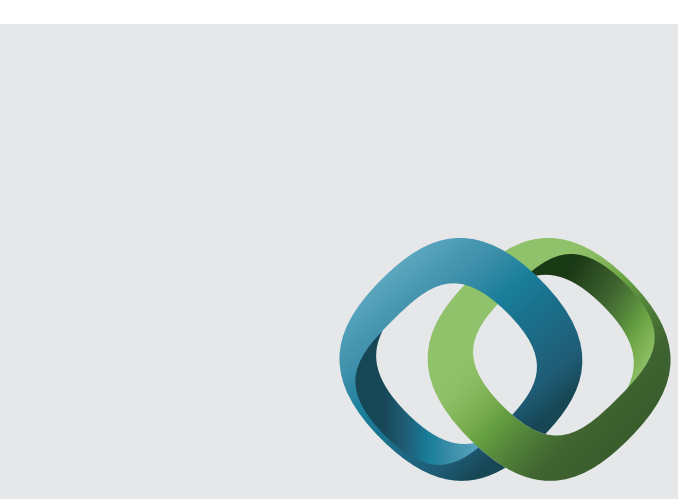

\section{Hindawi}

Submit your manuscripts at

http://www.hindawi.com
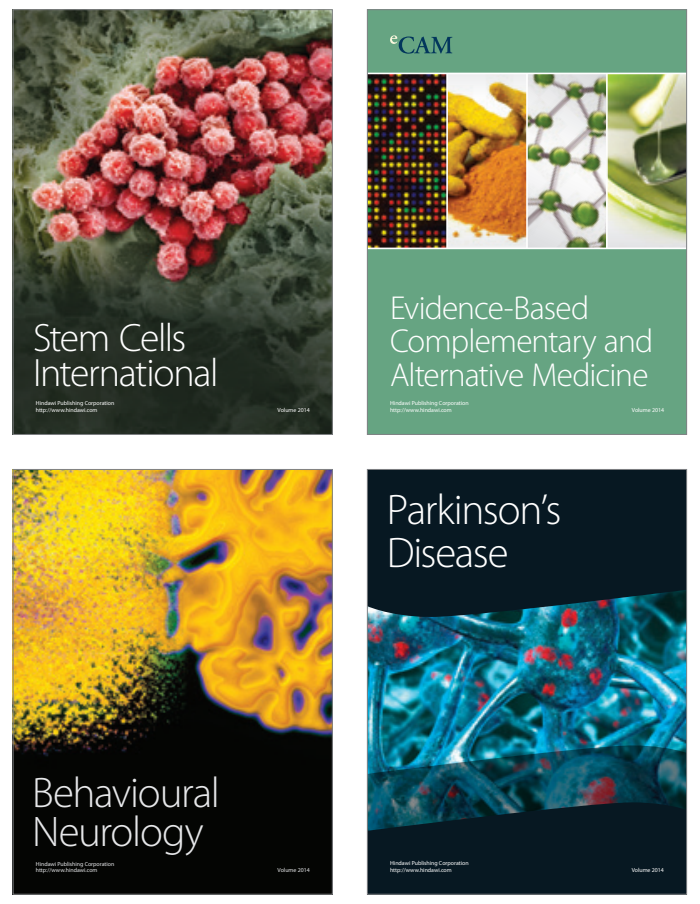
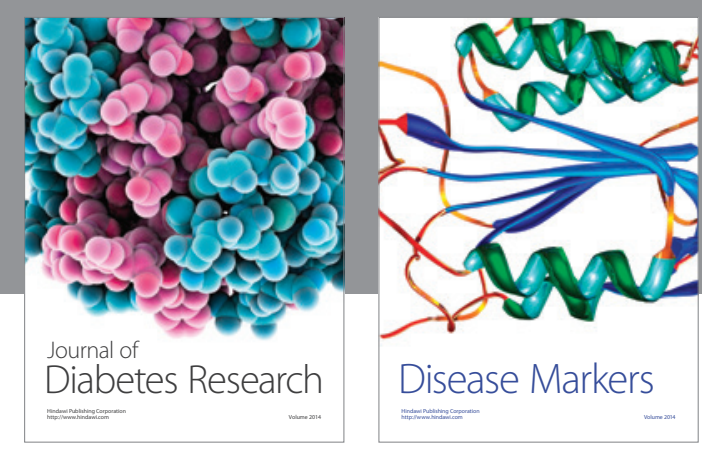

Disease Markers
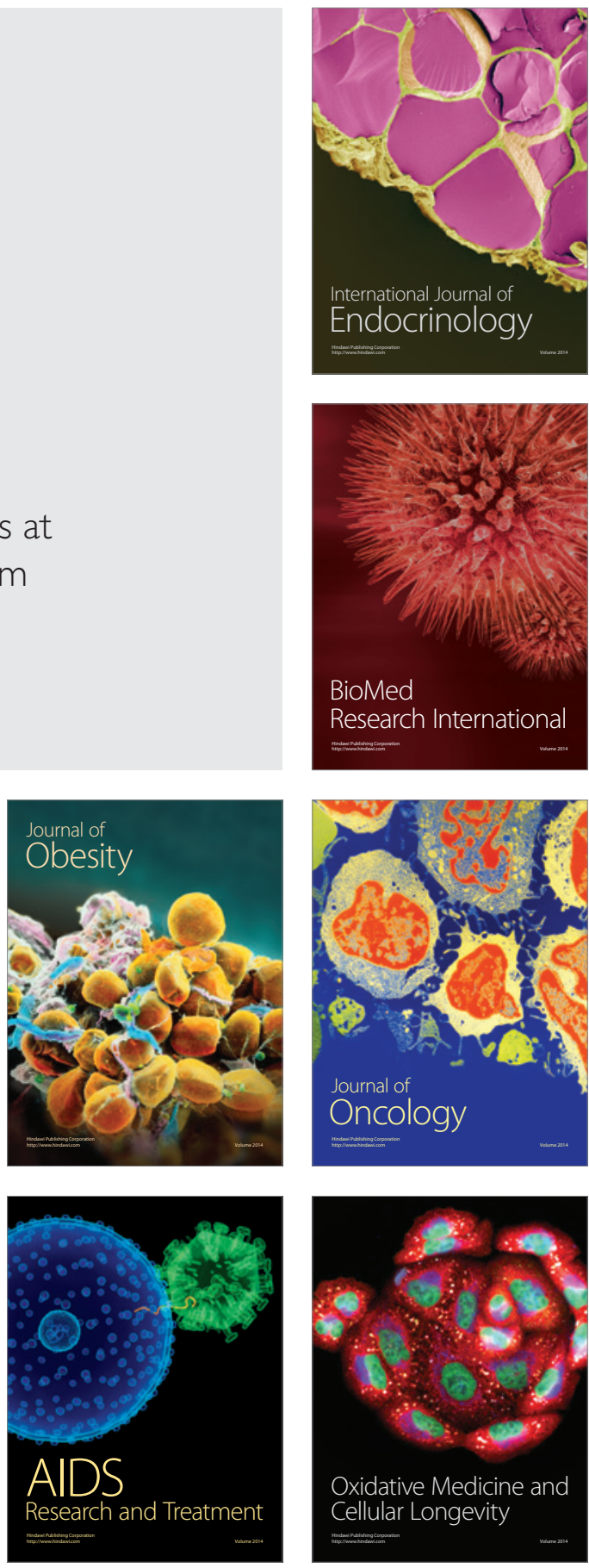